\title{
EXPERIMENTAL VALIDATION OF A CAPPILARY TUBE SIMULATION MODEL WITH REFRIGERANT MIXTURES FLOW
}

\begin{abstract}
F. A. S. Fiorelli
Universidade de São Paulo

Escola Politécnica

Departamento de Engenharia Mecânica

Av. Prof. Mello Moraes, 2231

05508-900, São Paulo, São Paulo, Brasil

fiorelli@usp.br

O. M. Silvares

Universidade de São Paulo

Escola Politécnica

Departamento de Engenharia Mecânica otavioms@usp.br

Centro Universitário do Inst.Mauá de Tecnologia Praça Mauá $\mathrm{n}^{\circ} 1$

09580-900, S. Caetano do Sul, São Paulo, Brasil otavioms@maua.br

ABSTRACT

This paper presents the experimental validation of a simulation model for refrigerant mixtures flow through capillary tubes. To perform such validation it was built an experimental apparatus using a blow-down process. It was carried out preliminary tests for characterization of experimental parameters: actual capillary tube diameters; relative roughness; and the heat losses in subcooling/quality control system. It was obtained almost 200 experimental points for R-407C (a zeotropic mixture) and R-410A (a near azeotropic mixture). Complete data set for each point consists of the measured pressure and temperature profiles, mass flow rate and mixture composition, as well as subcooling/quality control system inlet and outlet temperatures and heater electric power consumption for tests with two-phase flow capillary tube inlet conditions. Comparison of simulation and experimental data show a good agreement Main deviations are connected with the delay of vaporization phenomenon occurrence, experimentally verified by the authors.

Keywords: refrigeration, change of phase, simulation model.
\end{abstract}

\section{INTRODUCTION}

The main goal of the Montreal Protocol is the elimination of halogenated compounds. One of such substances is the HCFC 22, widely used in equipment for commercial refrigeration, commercial and household air conditioners and heat pumps. Unfortunately there is currently no pure substance that could be used as alternative without the need of great modifications in existing equipment. The use of zeotropic or near-azeotropic refrigerant mixtures is the most suitable alternative so far.

Using refrigerant mixtures demands new experimental and numerical studies to evaluate how they affect the performance of refrigeration cycles and design of cycle component. In this way, sizing of adiabatic capillary tubes using zeotropic mixtures is a subject of particular interest. It can be pointed out some works in this area in recent years (Bittle \& Pate, 1996; Chang \& Ro, 1996; Bittle et al., 1998; Sami \& Tribes, 1998; Sami et al., 1998; Fiorelli, 1998;1999; Wei et al., 1999; Jung et al., 1999; Motta et al., 2000; Fiorelli, 2000).

This paper presents the experimental validation of a simulation model for refrigerant mixtures flow through capillary tubes (Fiorelli et al., 1998). To perform such validation it was built an experimental apparatus using a blow-down process. It was carried out preliminary tests for characterization of some experimental parameters: actual capillary tube diameters by mercury filling a tube sample; relative roughness by measurement of pressure drop of an allliquid flow; and the heat losses in subcooling/quality control system by performing an energy balance for such subsystem.

It was obtained almost 200 experimental points for R-407C (a zeotropic mixture) and R-410A (a near-azeotropic mixture. Complete data set for each point consists of the measured pressure and temperature profiles, mass flow rate and mixture composition, as well as subcooling/quality control system inlet and outlet temperatures and heater electric power consumption for tests with two-phase flow capillary tube inlet conditions.

\section{MATHEMATICAL MODEL}

The main assumptions of the model are: steady state one dimensional flow, pure refrigerant or pure refrigerant mixture flow (no oil contamination), negligible axial and radial heat conduction in capillary tube walls, constant external UA' coefficient, no delay of vaporization, and homogeneous equilibrium two-phase flow model. According to Whalley (1996) the last assumption is a reasonable one for $\mathrm{G}>2000 \mathrm{~kg} / \mathrm{s} . \mathrm{m} 2$, which usually is true for capillary tubes.

For zeotropic and near-azeotropic mixtures it is assumed as "condensation" and "evaporation" temperatures the bubble temperatures at condensation and evaporation pressures. This assumption was made in order to establish a common basis for comparison. Figure 1 shows the main variables and parameters involved in capillary tubes simulation. The governing equations are mass, momentum and energy balances, given by Eqs. (1) to (3).

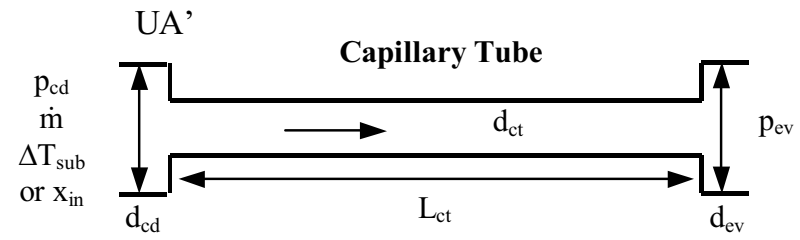

Figure 1. Variables of capillary tubes simulation model 


\section{TECNOLOGIA/TECHNOLOGY}

$$
\begin{aligned}
& \mathrm{dp} / \mathrm{dz}=-\mathrm{fvG}^{2} / 2 \mathrm{~d}_{\mathrm{ct}}-\mathrm{G}^{2} \mathrm{dv} / \mathrm{dz} \\
& \frac{\mathrm{dh}}{\mathrm{dz}}=-\mathrm{h}_{\mathrm{c}} \pi \mathrm{d}_{\mathrm{ct}}\left(\mathrm{T}_{\mathrm{ct}}-\mathrm{T}_{\mathrm{w}}\right) / \dot{\mathrm{m}}-\mathrm{G}^{2} \mathrm{vdv} / \mathrm{dz}
\end{aligned}
$$

Thermodynamic properties are calculated using REFPROP subroutines (NIST, 1996). Friction factor is calculated using Serghides correlation to Moody diagram (apud Kakaç et al., 1987), using Dukler correlation for calculation of homogeneous viscosity:

$$
\frac{1}{\sqrt{\mathrm{f}}}=\mathrm{A}_{5}-\frac{\left(\mathrm{A}_{5}-\mathrm{B}_{2}\right)^{2}}{\left(\mathrm{~A}_{5}+2 \mathrm{~B}_{2}+\mathrm{C}_{1}\right)}
$$

where:

$$
\begin{aligned}
& \mathrm{A}_{5}=-0.8686 \ln \left(\varepsilon_{\text {rel }} / 7.4+12 / \mathrm{Re}\right) \\
& \mathrm{B}_{2}=-0.8686 \ln \left(\varepsilon_{\text {rel }} / 7.4+2.51 \mathrm{~A}_{5} / \mathrm{Re}\right) \\
& \mathrm{C}_{1}=-0.8686 \ln \left(\varepsilon_{\text {rel }} / 7.4+2.51 \mathrm{~B}_{2} / \mathrm{Re}\right)
\end{aligned}
$$

Critical flow condition is verified by comparison of fluid velocity to sound speed at capillary tube end, given by:

$$
\mathrm{c}^{2}=(\partial \mathrm{p} / \partial \rho)_{\mathrm{s}=\mathrm{const}}
$$

Internal heat transfer coefficient hc is given, for liquid region, by Dittus-Böelter equation. For two-phase region it is used a modified Dittus-Böelter equation (cf. Pate, 1982), Eq. (9), using the average velocity and liquid properties. Exponent $\mathrm{n}$ is 0.4 for heating or 0.3 for cooling.

$$
\frac{\mathrm{h}_{\mathrm{c}} \mathrm{d}_{\mathrm{ct}}}{\mathrm{k}_{1}}=0.023 \operatorname{Re}_{1}^{0.8} \operatorname{Pr}_{1}^{\mathrm{n}}\left(\frac{1-\mathrm{x}}{1-\alpha}\right)^{0.8}
$$

Pressure drops at inlet contraction for two-phase flow conditions, as well as at outlet expansion for non critical flow conditions are calculated by Eqs. (10) and (11) respectively (cf. Collier \& Thome, 1996), where $\sigma_{\mathrm{cd}}=\mathrm{A}_{\mathrm{cd}} / \mathrm{A}_{\mathrm{ct}}, \sigma_{\mathrm{ev}}=\mathrm{A}_{\mathrm{ct}} / \mathrm{A}_{\mathrm{ev}}$ and $\mathrm{C}_{\mathrm{c}}=\mathrm{f}(\sigma)$. For subcooled liquid inlet conditions pressure drop at inlet is calculated by Eq. (12) (cf. Idelcik, 1960).

$$
\begin{aligned}
& p_{c d}-p_{\text {in }}=\frac{G^{2} v}{2}\left[\left(\frac{1}{C_{c}}-1\right)^{2}+\left(1-\frac{1}{\sigma^{2}}\right)\right] \\
& p_{\text {out }}-p_{\text {ev }}=G^{2} v \sigma(1-\sigma) \\
& p_{c d}-p_{\text {in }}=0.75 G^{2} v
\end{aligned}
$$

Capillary tube wall temperature $T_{\mathrm{w}}$ is given by:

$$
\mathrm{T}_{\mathrm{w}}=\frac{\mathrm{h}_{\mathrm{c}} \pi \mathrm{d}_{\mathrm{ct}} \mathrm{T}_{\mathrm{ct}}+\mathrm{UA}^{\prime} \mathrm{T}_{\mathrm{o}}}{\mathrm{h}_{\mathrm{c}} \pi \mathrm{d}_{\mathrm{ct}}+\mathrm{UA}^{\prime}}
$$

From conservation equations it is obtained $p$ and $\mathrm{h}$ along the capillary tube. From these two profiles and
I nen, Irom $\mathrm{p}$ and $\mathrm{I}$ as well as assuming l1quid-vapor thermal and hydrodynamic equilibrium, liquid and vapor composition along the capillary tube is calculated. From composition, $\mathrm{T}$ and $\mathrm{p}$ it is obtained saturated liquid and vapor properties. At last, from $\mathrm{h}$ it is calculated $\mathrm{x}$ profile and mixture properties. Equations (14) to (19) show these calculations.

$$
\begin{aligned}
& T_{c t, i}=f\left(p_{i}, h_{i}, y_{1}, \ldots, y_{n}\right) \\
& y_{1,1, i}, \ldots, y_{n, l, i}=f\left(p_{i}, T_{i}, y_{1}, \ldots, y_{n}\right) \\
& y_{1, v, i}, \ldots, y_{n, v, i}=f\left(p_{i}, T_{i}, y_{1}, \ldots, y_{n}\right) \\
& h_{1, i}=f\left(p_{i}, x=0, y_{1,1}, \ldots, y_{n, 1}\right) \\
& h_{v, i}=f\left(p_{i}, x=1, y_{1, v}, \ldots, y_{n, v}\right) \\
& x_{i}=\left(h_{i}-h_{1, i}\right) /\left(h_{v, i}-h_{1, i}\right)
\end{aligned}
$$

A computational program was developed for numerical simulation using the EES software (EES, 1997). It uses an implicit finite difference method for numerical integration of the governing equations and solves the resulting system of nonlinear algebraic equations using a modified Newton-Raphson method. The step variable used is the pressure drop. Model preliminary experimental validation for single refrigerants simulation (CFC-12 and HFC-134a) was presented previously (Fiorelli et al., 1998). The calculated mass flow rates agree with experimental and literature data within $10 \%$.

\section{EXPERIMENTAL APPARATUS}

Figure 2 presents a flowchart of the experimental apparatus built to this study. It is used a blow-down process in order to provide an accurate control of the process parameters. Refrigerant is initially stored upward the test section in a high-pressure reservoir (two bladder accumulators of 100 litres each). Such high pressure is provided by nitrogen filling of the bladders.

Test section exit is connected to a low-pressure reservoir. Low pressure is obtained by refrigerant condensation provided by chilled ethylene-glycol/water mixture flowing through a coil inside the reservoir. By pressure difference the refrigerant flows from the highpressure to the low-pressure reservoir through the test section where is placed the capillary tube (CT). Fluid return is also made by pressure difference. Pressure is raised in the low-pressure reservoir by means of two heaters, as long as pressure is lowered in the highpressure reservoir by releasing nitrogen.

Parameters measured in test section are the pressure and temperature profiles along $\mathrm{CT}$, mass flow rate through $\mathrm{CT}$, electric power consumption of subcooling/quality final control heater, and mixture composition at $\mathrm{CT}$ inlet. Ten strain-gage type pressure transducers $( \pm 0.1 \%$ range value uncertainty) measure CT pressure profile. Temperature profile is obtained by 18 T-type thermocouples soldered to the tube wall $\left( \pm 0.3^{\circ} \mathrm{C}\right.$ uncertainty). It is also used two Pt-100 thermoresistances at capillary tube inlet and subcooling/quality control system inlet $\left( \pm 0.2^{\circ} \mathrm{C}\right.$ uncertainty). 


\section{TECNOLOGIA/TECHNOLOGY}

Corılos-type IIowmeter ( \pm U. $1 \%$ range value uncertainty). Electric power consumption of subcooling/quality final control heater is obtained by a wattmeter $( \pm 1.0 \%$ reading uncertainty). This power consumption is used to evaluate, by energy balance, the quality for two-phase capillary tube inlet conditions. Mixture composition (in mass percentage) is monitored by a gas chromatograph with $\pm 1.0 \%$ uncertainty.

The main parameters to be controlled in each run are the $\mathrm{CT}$ inlet and outlet pressures, and $\mathrm{CT}$ inlet subcooling or quality. CT Inlet pressure is controlled by a regulator (pre-control) and a PID control/solenoid valve system (final control) on $\mathrm{N}_{2}$ line. Outlet pressure is controlled by a PID control/solenoid valve system on ethylene-glycol line. By controlling the glycol flow rate, it is possible to control condenser pressure and, as a result, the CT outlet pressure. At last, subcooling/quality control is achieved by a heating system divided in two parts. It is performed a pre-heating by a coil immersed in a hot water constant-temperature bath. Final adjustment of subcooling or quality is obtained by a $5.0 \mathrm{~W} / \mathrm{m}$ tape heater and a PID controller (subcooling) or manual control (quality).

\section{EXPERIMENTAL ANALYSIS}

First step in obtaining the experimental data was the characterisation of some experimental parameters: actual CT diameters and relative roughness, the heat losses in subcooling/quality control system, and the instrumentation effect on mass flow rate.

Actual CT internal diameters were measured by filling a CT sample with mercury. This procedure provides the average diameter with $\pm 1.0 \%$ uncertainty. CT diameters used in this work were $1.101 \mathrm{~mm}, 1.394 \mathrm{~mm}$ and $1.641 \mathrm{~mm}$.

Relative roughness $\varepsilon_{\text {rel }}$ was evaluated by measuring the pressure losses of an all-liquid R-410A refrigerant flow through CT. From these pressure losses it was possible to calculate the friction factors. Using the Colebrook equation and the calculated friction factors,
F. A. S. Fiorelli et al. Experimental Validation Of...

Iisted diameters were 2.354x10;, 3.604xI0;, and $2.193 \times 10^{-4}$ respectively. This smaller values than others reported in open literature are due to manufacturing process, that includes a polishing phase.

Heat losses in subcooling/quality control system were evaluated to determine how much of the electric power provided to the tape resistance was actually used to raise refrigerant enthalpy. Heat losses were evaluated similarly to the relative roughness, by measuring inlet and outlet temperatures, as well as mass flow rate and resistance electric power consumption of an all-liquid refrigerant flow through the heat exchanger.

Instrumentation, particularly the pressure taps, may significantly reduce refrigerant mass flow rate through the capillary tube due to the introduction of an additional local pressure loss or the shift of flashing point, since the pressure taps may act as active cavities for bubble nucleation. According to literature (cf. Meyer $\&$ Dunn, 1998), the reduction in mass flow rate may be up to $15 \%$. Another factor that can affect capillary tube behaviour is thermocouples soldering on tube wall. This would locally change heat transfer, once thermocouples act as fins and may consequently create conditions for appearance of active cavities where flashing inception takes place.

The instrumentation effect was evaluated by comparing a set of 54 experimental points, obtained for a given capillary tube without instrumentation, with a second data set obtained for the same operational conditions after the instrumentation were attached to the capillary tube. This comparison showed a small effect of instrumentation on capillary tube performance (about $1.6 \%$ mass flow rate average reduction).

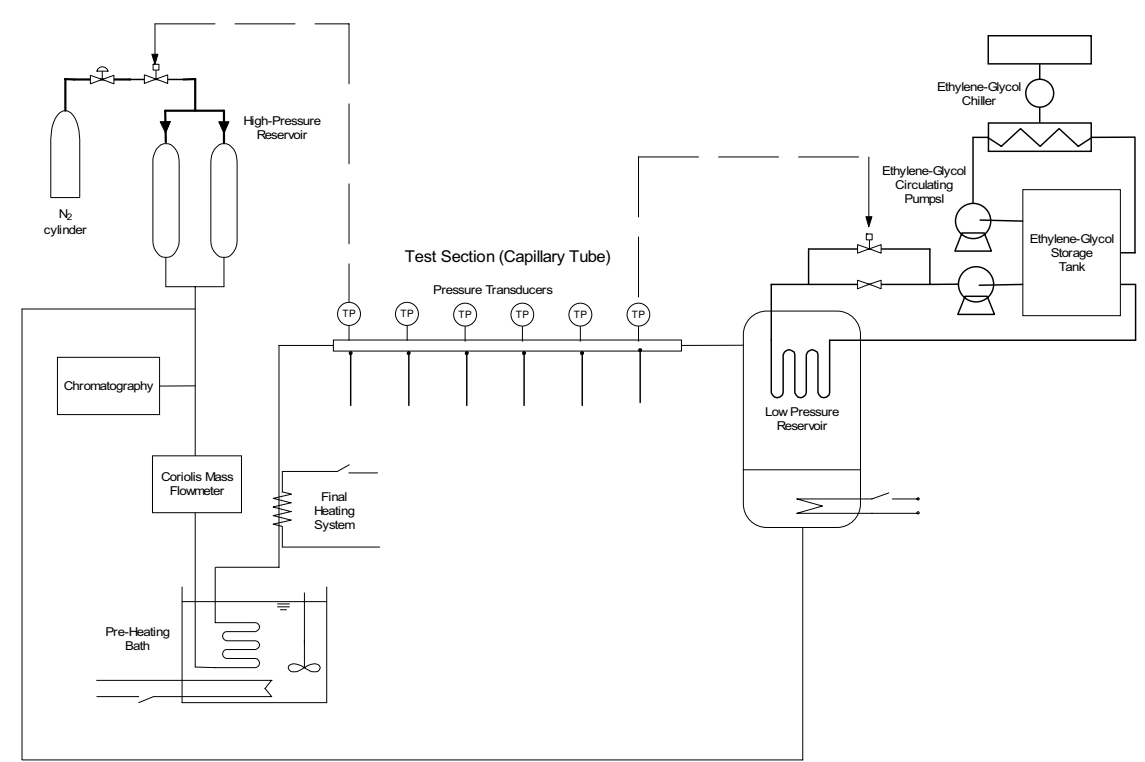

Figure 2. Experimental apparatus flowchart 


\section{TECNOLOGIA/TECHNOLOGY}

obtainea. I ne experimental proceaure consisted in I1xing inlet and outlet pressure, as well as the initial subcooling or quality, and then starts the test/data acquisition. Once the first steady-state operational condition was reached, the time and a data set were recorded. Then a new subcooling or quality value was fixed, and when a new steady-state operational condition was reached again, the time and a data set were recorded. The same steps were performed to the third point. During the run, three to five chromatographic analyses were also performed to evaluate refrigerant composition for that run.

Steady-state verification criterion was the elapsed time since last parameters setting. During preliminary tests, it took about 50 minutes to reach the first steady state condition and around 20 minutes for subsequent ones. Thus, an initial interval of $1 \mathrm{~h}$ and subsequent intervals of 30 min were adopted for reaching steady-state conditions. This criterion was adopted in parallel to operator's monitorship during the tests. Later data analysis showed that the adopted standard intervals were suitable to all performed tests.

Once the experimental apparatus was mounted and adjusted, the data survey was carried out. Twentyeight runs were performed for R-410A, totalling 84 experimental points for $\mathrm{d}_{\mathrm{ct}}=1.101 \mathrm{~mm}$ and $\mathrm{L}_{\mathrm{ct}}=1.5 \mathrm{~m}$, and 38 runs were performed for R-407C, totalling 113 experimental points for several geometries and operational conditions. The complete data set for each point consists of the measured pressure and temperature profiles, mass flow rate and mixture composition, and inlet and outlet temperatures subcooling/quality control system. For tests with two-phase flow capillary tube inlet conditions, the data set also includes the heater electric power consumption, used to evaluate inlet quality. A table set containing all experimental data can be found in Fiorelli et al. (2002).

Figure 3 shows typical experimental temperature profiles for subcooled and two-phase inlet conditions. Pressure profiles are presented in Figs. 4 and 5 for both refrigerant mixtures. In this figures it is also shown the saturation pressure profile evaluated for the given temperature profile and refrigerant composition, assuming zero quality.

These figures also show that temperature, pressure and composition measurements are consistent, once there is a good agreement between measured and calculated pressure profiles for R-410A. By the other hand, for R$407 \mathrm{C}$ it can be seen in fig. $5 \mathrm{~b}$ that there is a detachment between the measured pressure profile and the calculated (bubble pressure) one as the quality grows. This figure also shows that the measured profile approaches the calculated dew pressure profile. Such behaviour is expected once a zeotropic mixture presents composition variation during phase change process, which leads to a saturation temperature glide (as well as a pressure glide) associated to this composition variation. In order to get agreement quality or composition proille along tne IIow. It can aiso be noticed in Figs. 4 and 5 the occurrence of the delay of vaporization, detailed on Fig. 6. This phenomenon occurred for most of the subcooled inlet runs for both fluids.

\section{MODEL VALIDATION}

Figure 7 shows the comparison between calculated and experimental mass flow rate values for R410A for both subcooled and two-phase inlet condition. For subcooled inlet conditions the simulation model underpredicts mass flow rate with an average deviation of $4.0 \%$ and a dispersion of $\pm 2.5 \%$. Similar behaviour is observed for two-phase inlet conditions, but deviation are greater ( $-5.8 \%$ average deviation and $\pm 3.0 \%$ dispersion).

It can be noticed that the error increases as subcooling decreases and quality increases, indicating that as the two-phase flow region length increases, both models loose accuracy. The larger the length of two-phase region, the bigger is the quality value at capillary tube outlet. So it can be said that for higher quality values, the model becomes less suitable for representing the physical phenomenon.

Figure 8 presents the comparison of measured and calculated pressure and temperature profiles for a typical run with subcooled inlet conditions. It can be verified a good agreement between such profiles, with exception of the region where delay of vaporisation occurs. This phenomenon is one of the causes that lead to the mass flow rate underestimation. Smaller errors were obtained for those runs where such phenomenon did not occurred. In this sense, the introduction of a prediction model for the delay of vaporisation could improve overall capillary tube simulation model. For example, by adding the $\Delta \mathrm{p}_{\text {sat }}$ values obtained from experimental data to the inlet pressure provided to simulation model it is obtained an average error reduction from $-4.0 \%$ to $-1.5 \%$.

Figures 9 and 10 show the comparison between experimental and calculated data for R-407C. For subcooled inlet, the model presents a similar behaviour to that for R-410A: mass flow rate underestimation with $4.0 \%$ average error and $\pm 2.5 \%$ dispersion. However, deviations do not present an increasing tendency as subcooling decreases. For two-phase inlet conditions, the model presents an average error of $+0.1 \%$. In this case, models behaviour is quite different from that for R-410A, once there is no tendency to underestimate mass flow rate.

Agreement between measured and calculated profiles is similar to that for R-410A: there is a good agreement, with exception of the region where delay of vaporisation occurs. Introduction of experimental values for delay of vaporization $\Delta \mathrm{p}_{\text {sat }}$ changes average deviation from $-4.0 \%$ to $+1.5 \%$. 


\section{TECNOLOGIA/TECHNOLOGY}

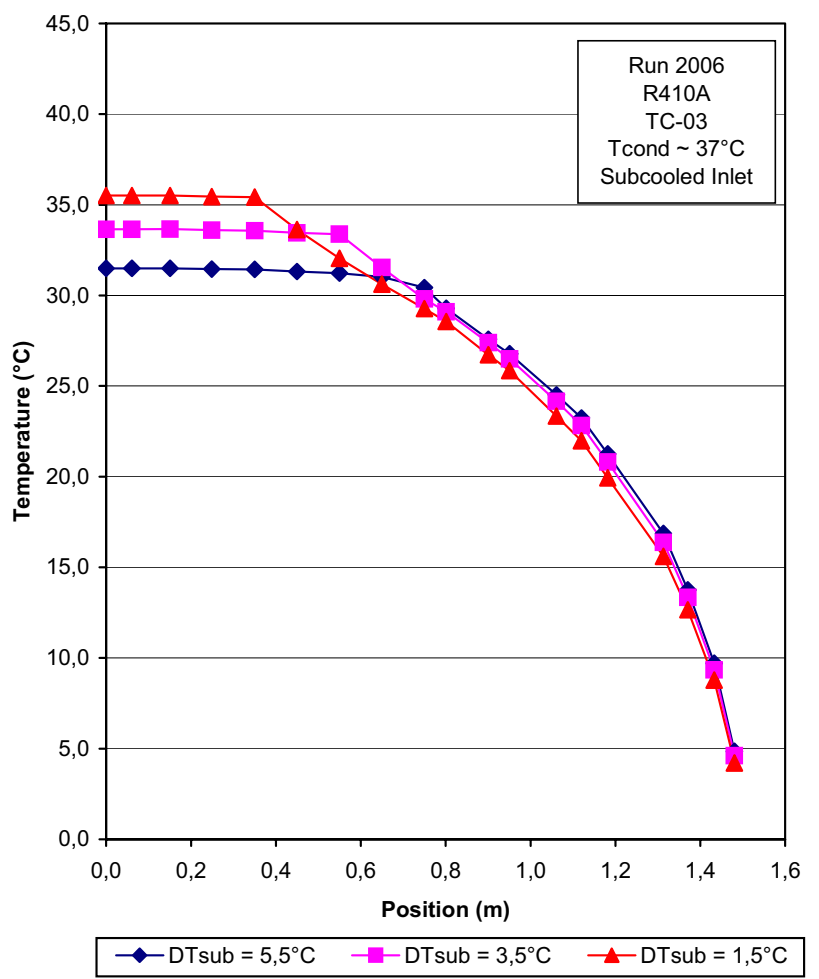

(a) subcooled inlet conditions
F. A. S. Fiorelli et al. Experimental Validation Of...

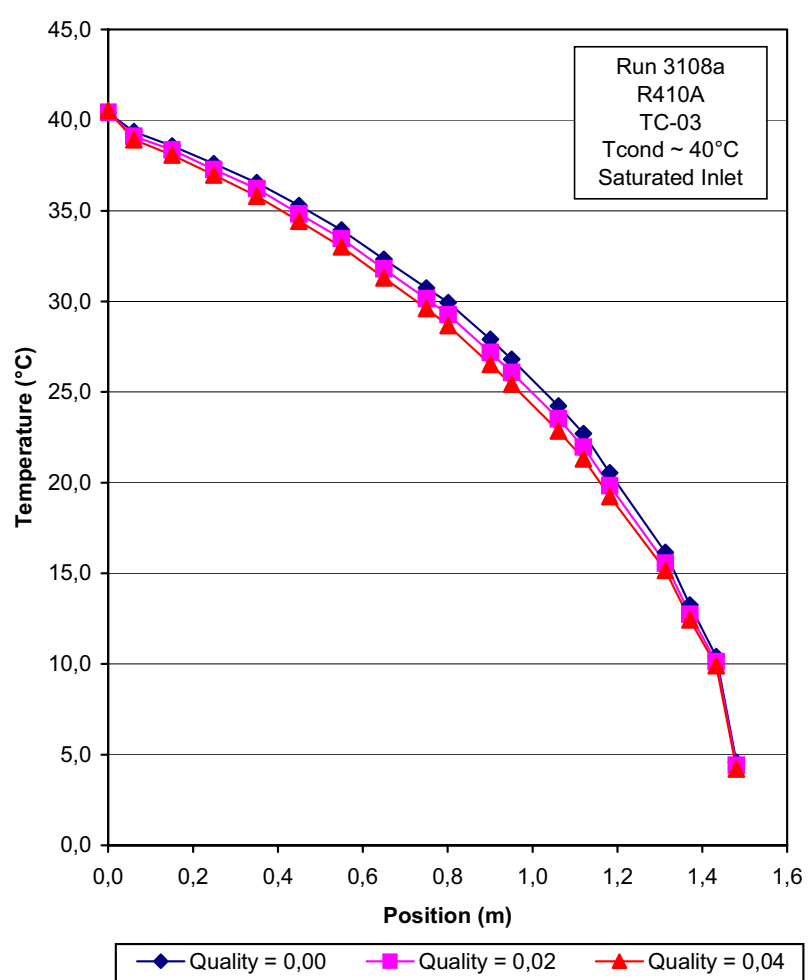

(b) two-phase inlet conditions

Figure 3. Typical temperature profiles.

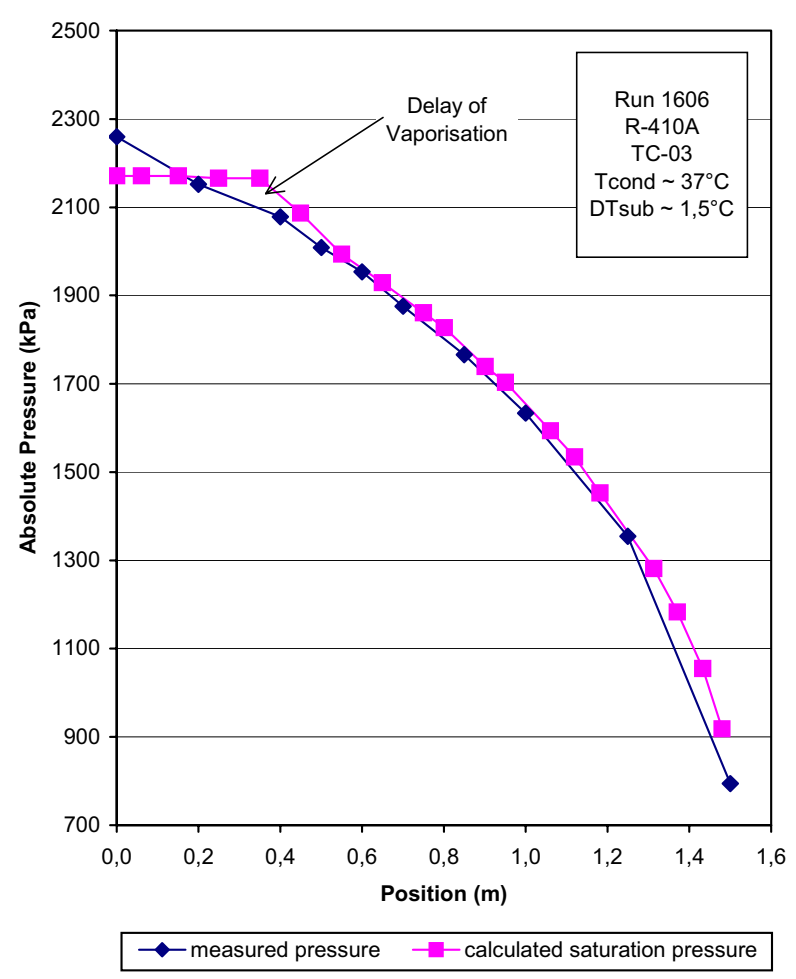

(a) subcooled inlet conditions

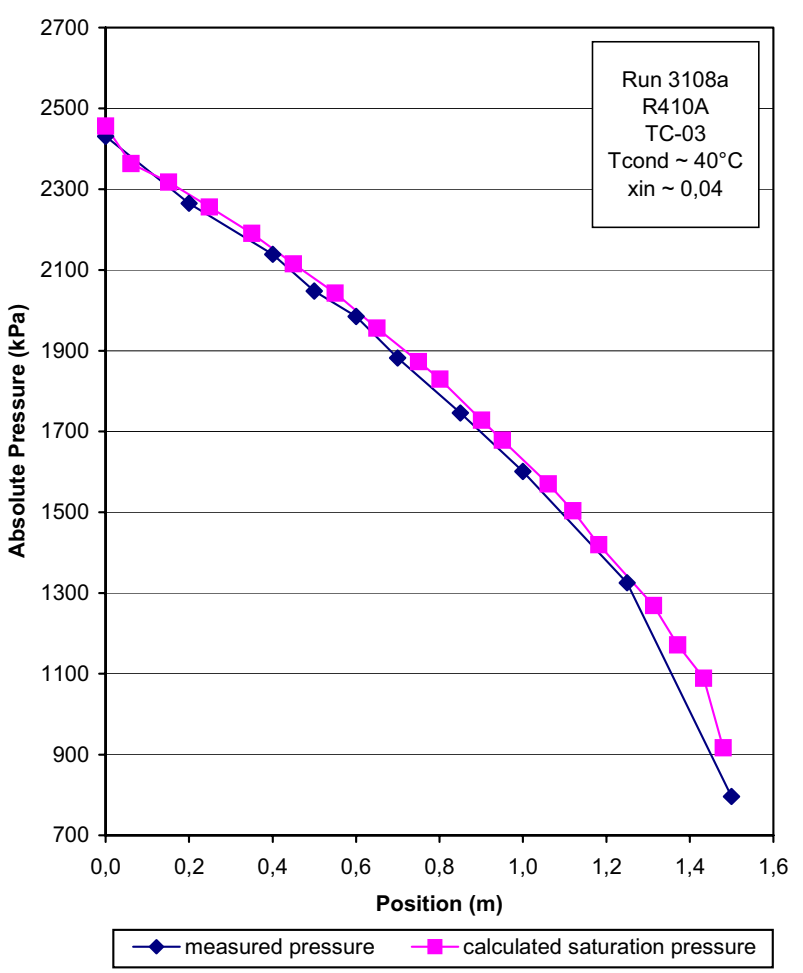

(b) two-phase inlet conditions

Figure 4. Pressure profiles for R-410A. 


\section{TECNOLOGIA/TECHNOLOGY}

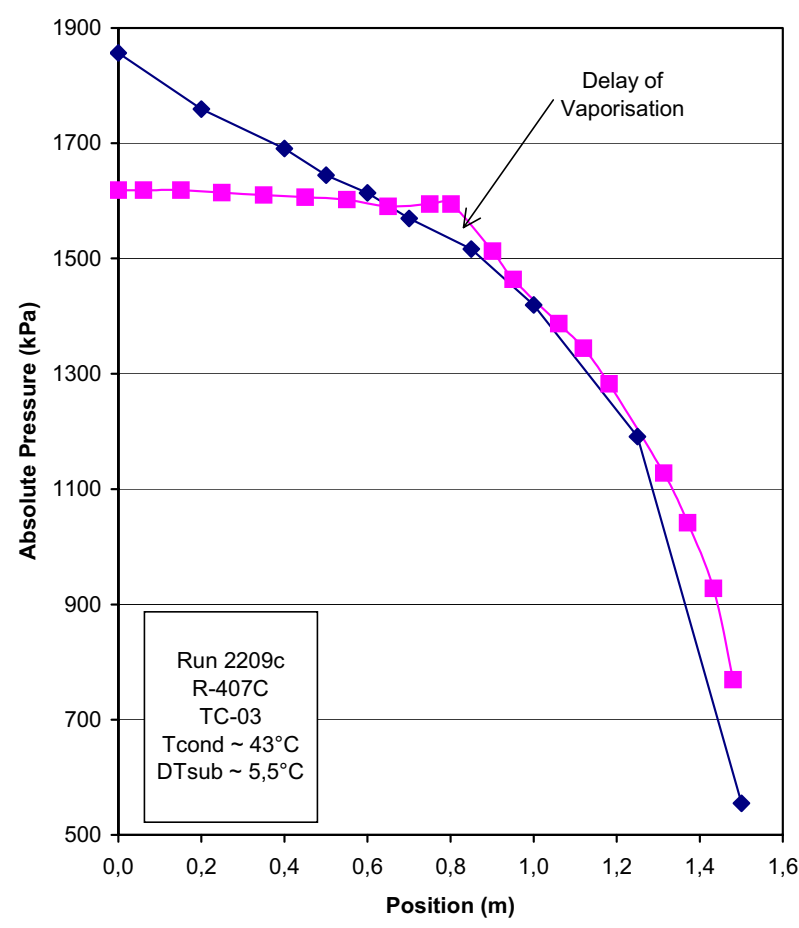

measured pressure $\rightarrow-$ calculated saturation pressure

(a) subcooled inlet conditions
F. A. S. Fiorelli et al. Experimental Validation Of...

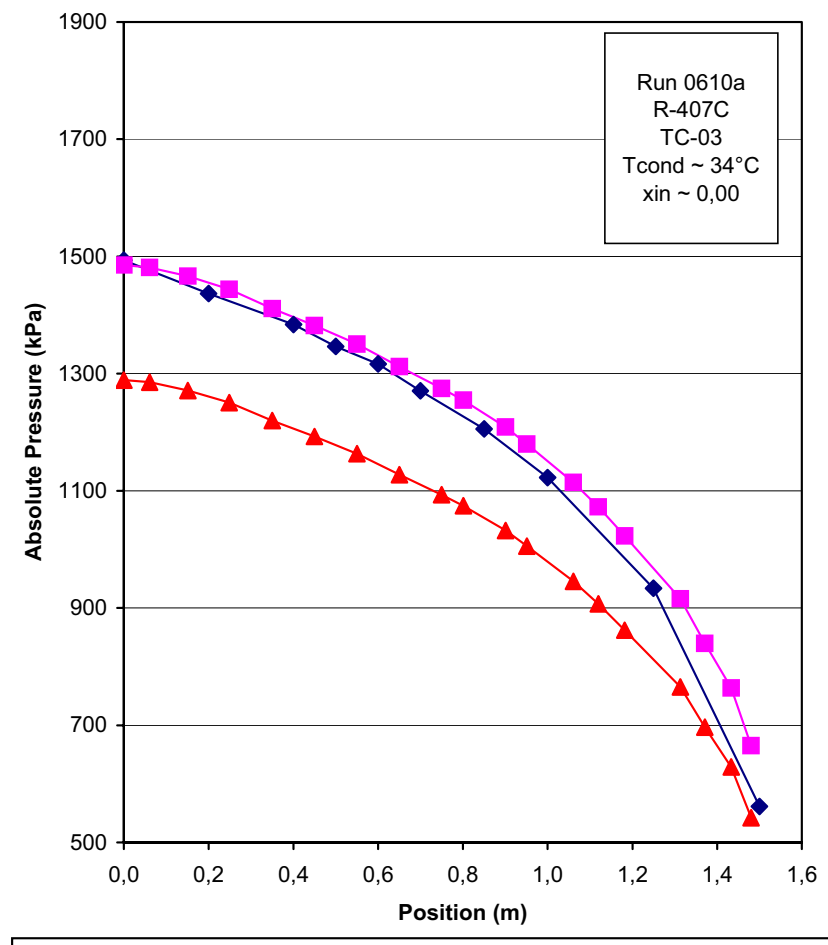

-Pressure Profile $-\leftarrow$-Bubble Pressure Profile $\rightarrow-$ Dew Pressure Profile

(b) two-phase inlet conditions

Figure 5. Pressure profiles for R-407C.

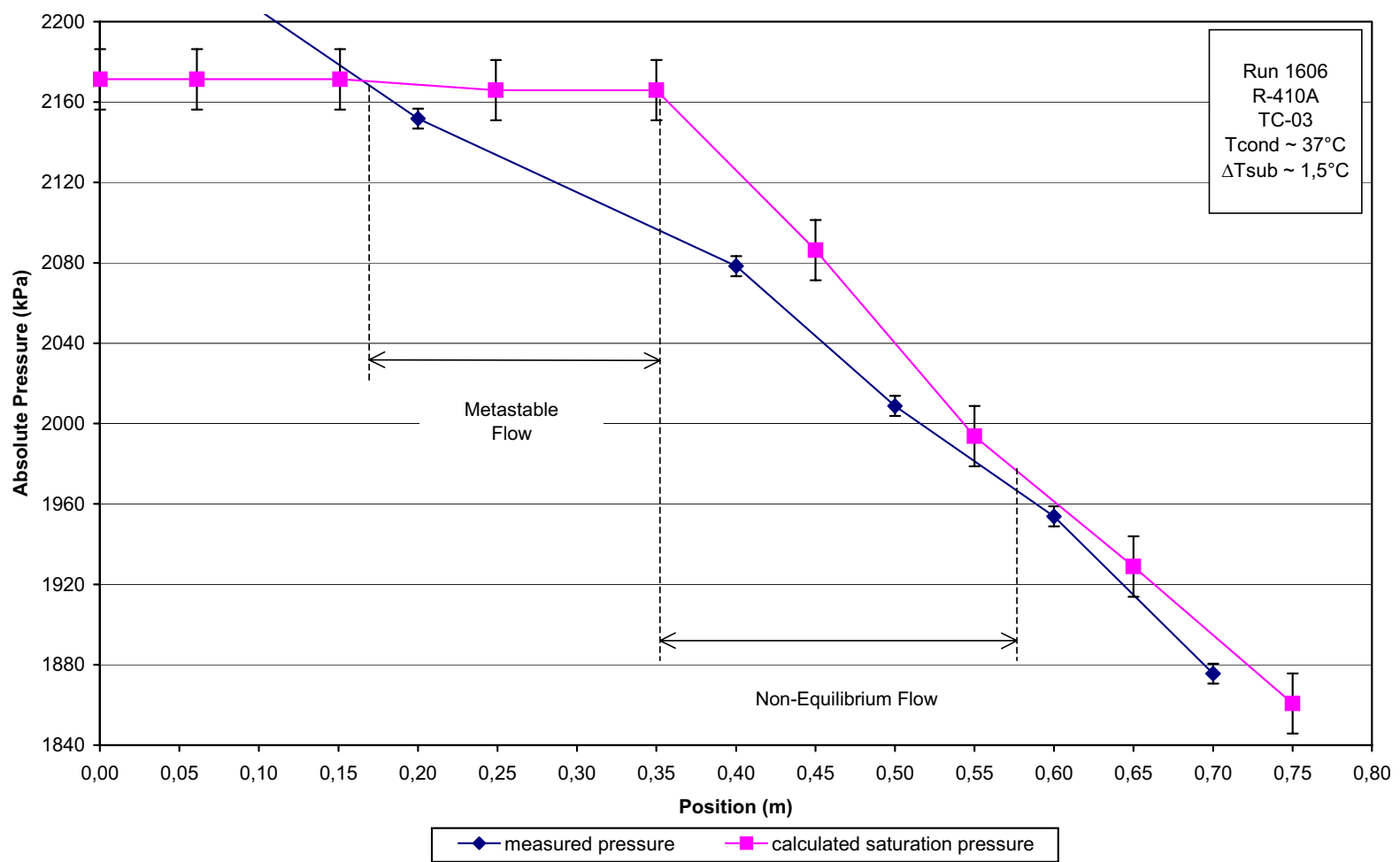

Figure 6. Detail of pressure profile showing the delay of vaporisation occurrence. 


\section{TECNOLOGIA/TECHNOLOGY}

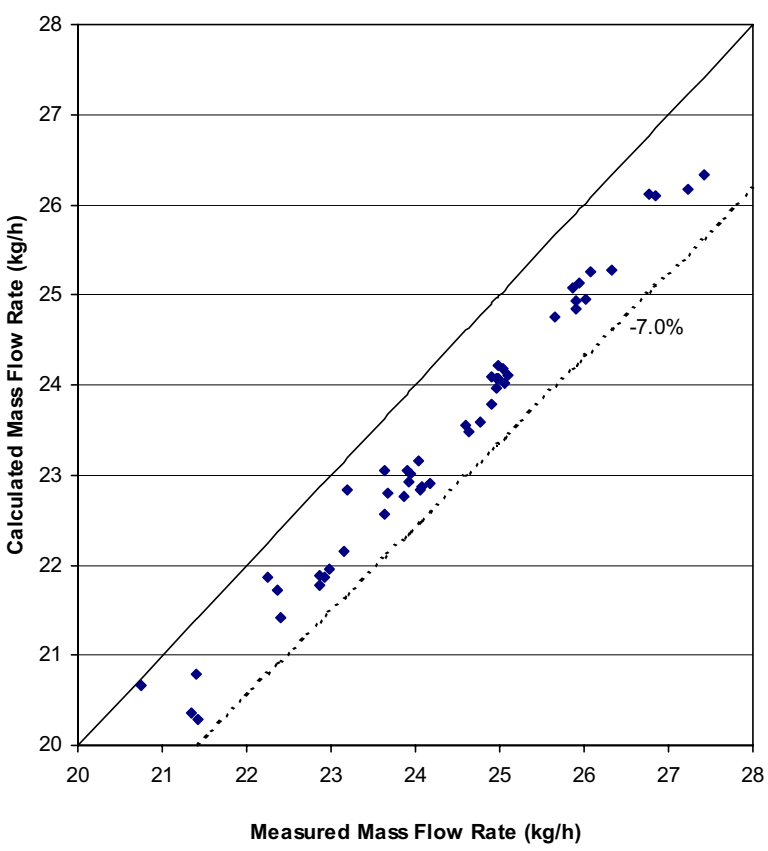

(a) subcooled inlet conditions

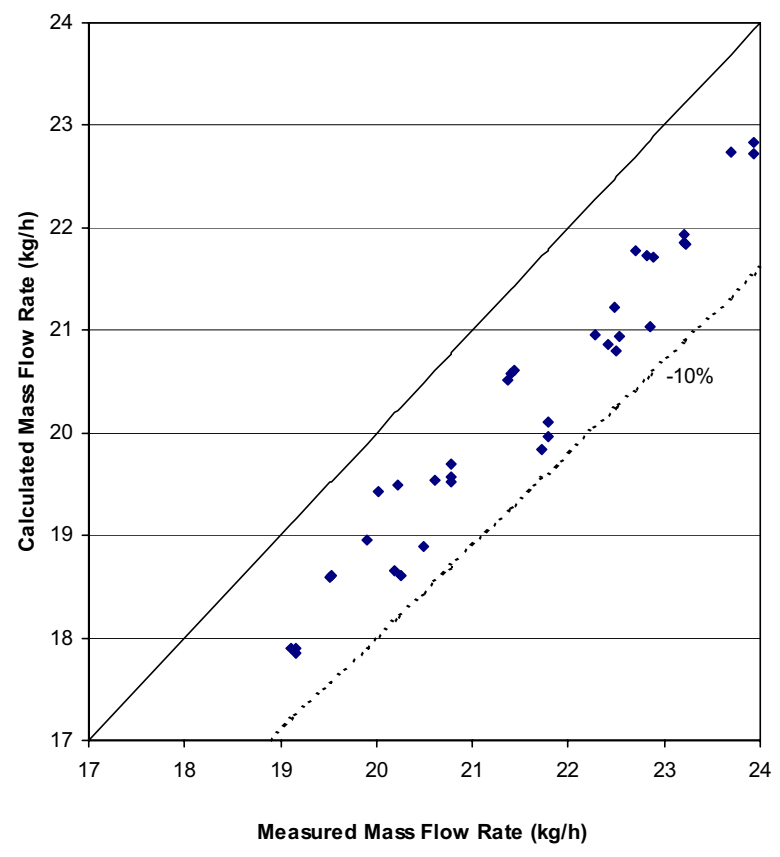

(b) two-phase inlet conditions

Figure 7. Comparison between measured and calculated mass flow rate for R-410A

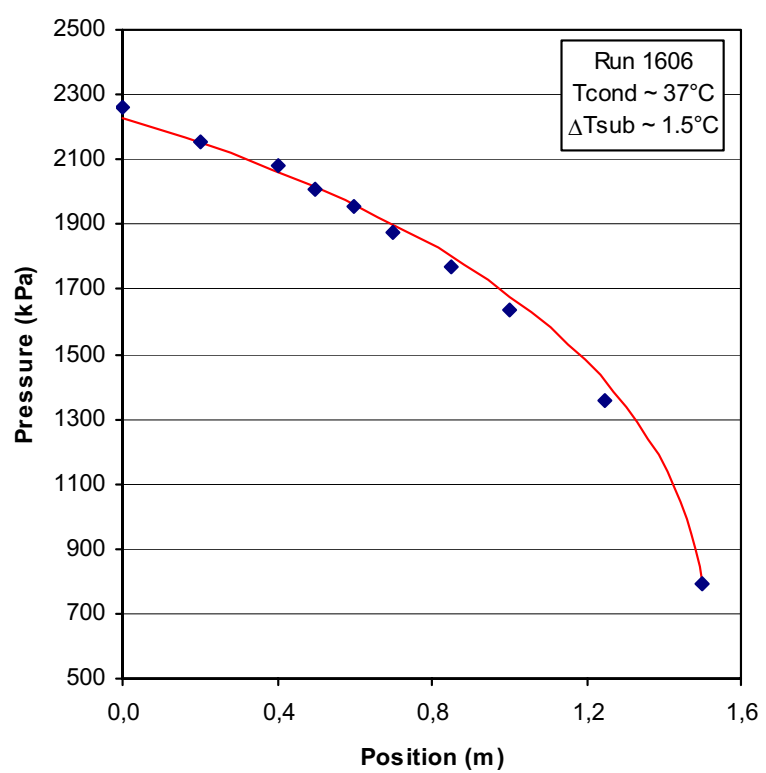

- Experimental Profile

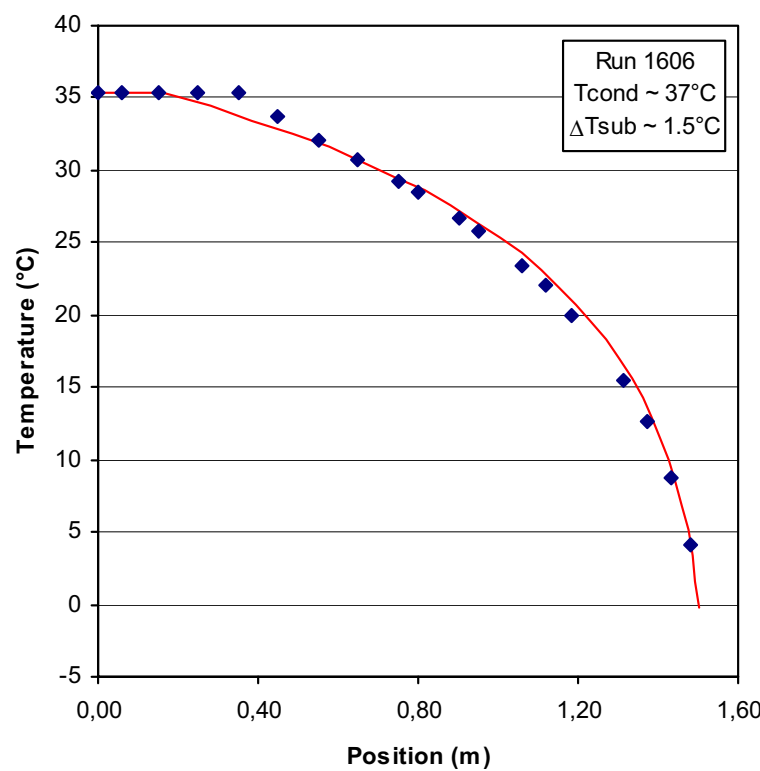

- Measured Profile - Calculated Profile

Figure 8. Pressure and temperature profiles for R-410A: subcooled inlet conditions 


\section{TECNOLOGIA/TECHNOLOGY}

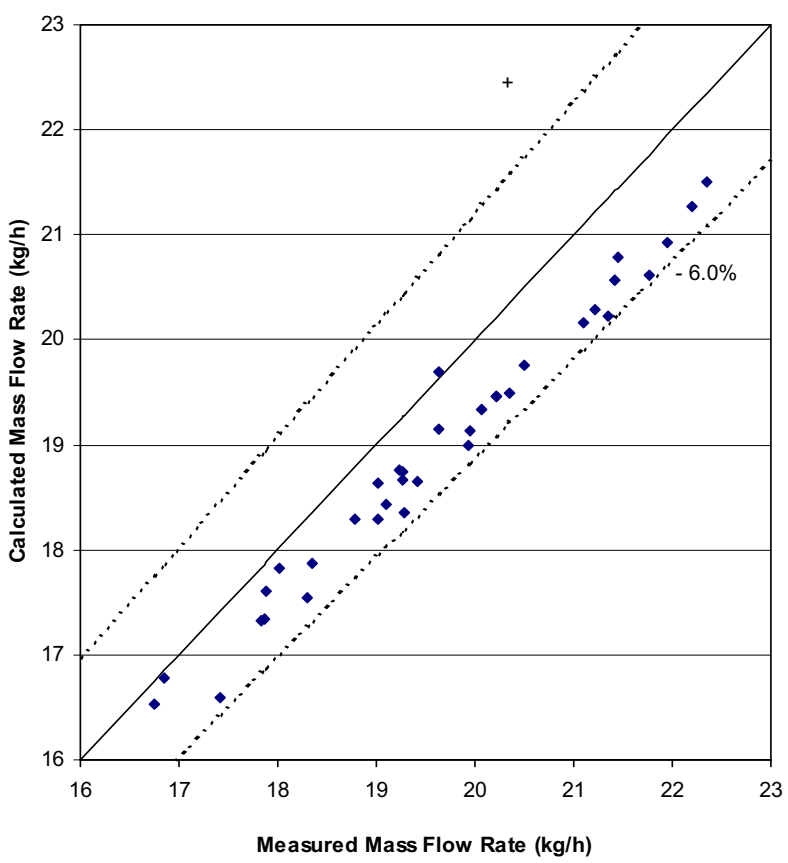

(a)

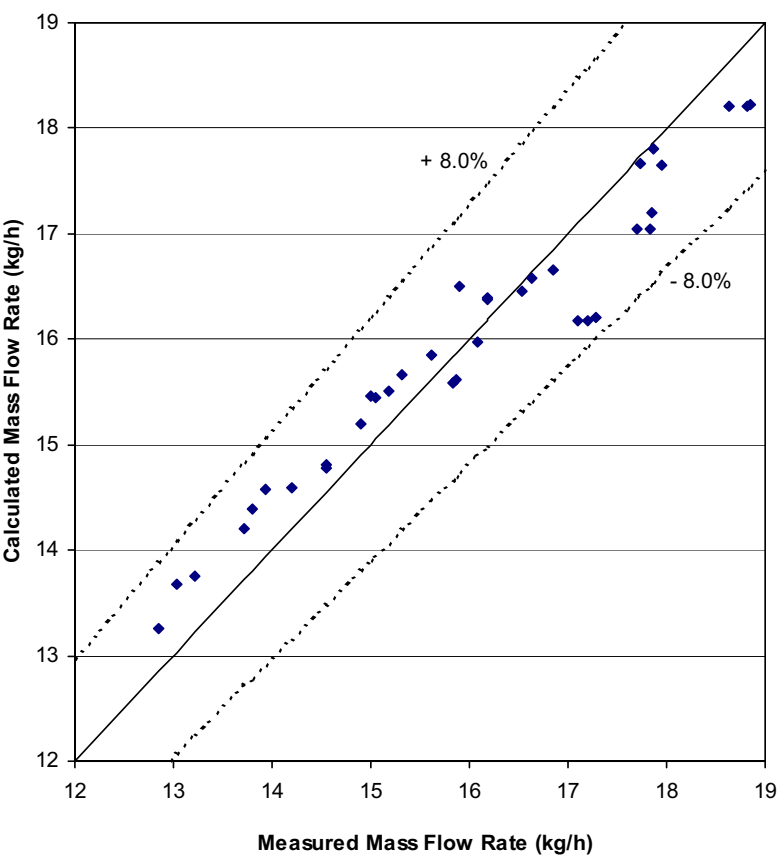

(b)

Figure 9. Comparison between measured and calculated mass flow rate for R-407C: (a) subcooled and (b) two-phase inlet conditions.

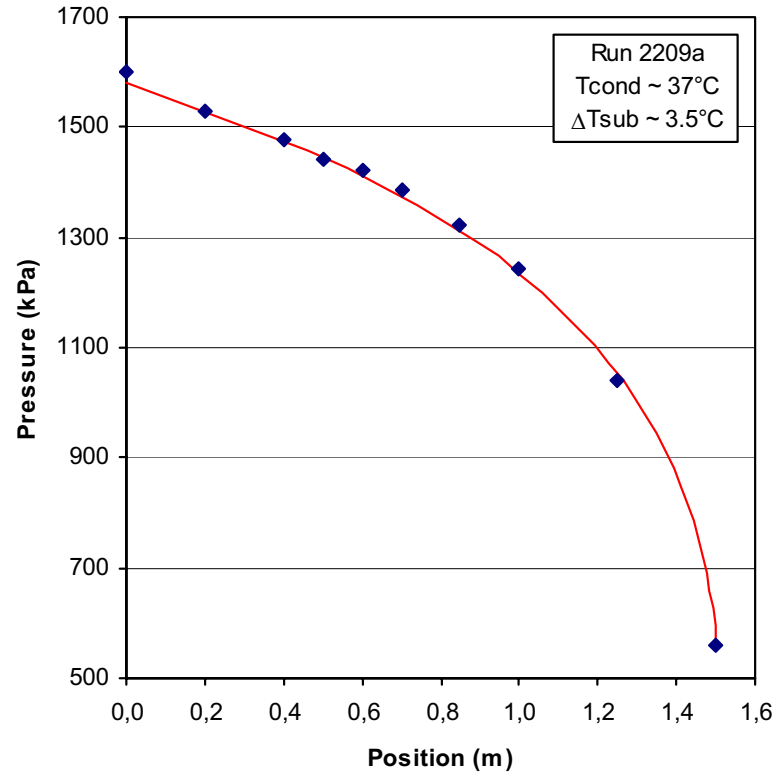

- Measured Profile Calculated Profile

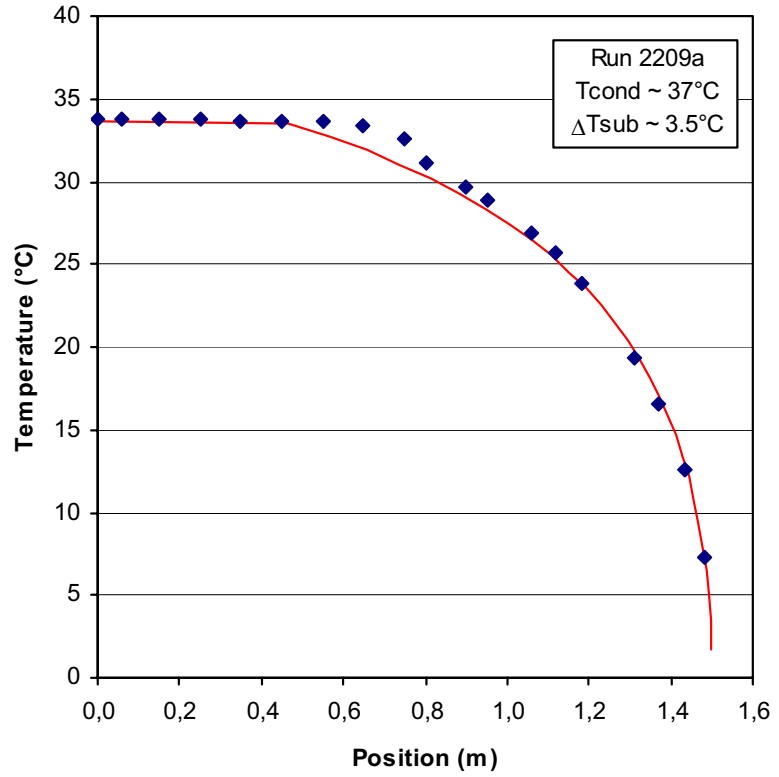

- Measured Profile _ Calculated Profile

Figure 10. Pressure and Temperature Profiles for R-407C - Subcooled Inlet Conditions 


\section{CONCLUSION}

This work presents the a simulation model for refrigerant mixtures flow through adiabatic capillary tubes. It is discussed the main assumptions for the model, and it is presented the governing and constitutive equations.

Experimental validation shows the model presents the same error level when compared to measured values of mass flow rate, temperature and pressure profiles for both R-410A and R-407C. The validation also shows the occurrence of the delay of vaporisation, which leads to a mass flow rate underestimation tendency. Taking account this phenomenon reduced error level for both fluids.

The presented results show that the model is suitable for simulation of adiabatic capillary tubes with refrigerant mixtures flow.

\section{ACKNOWLEDGEMENTS}

The authors would like to acknowledge FAPESP (São Paulo State Research Supporting Foundation) for financial support to this study.

\section{REFERENCES}

—. 1996. NIST Thermodynamic Properties of Refrigerants and Refrigerant Mixtures Database (REFPROP) Version 5.0 User's Guide, U.S. Dept. of Commerce, Gaithersburg.

—. 1997. EES User's Guide, F-Chart Software.

Bittle, R.R., Pate, M.B. 1996. “A Theoretical Model for Predicting Adiabatic Capillary Tube Performance with Alternative Refrigerants", ASHRAE Trans., vol. 102(2), 52-64.

Bittle, R.R. et al. "A Generalized Performance Prediction Method for Adiabatic Capillary Tubes", HVAC\&R Research, vol. 4(1), 27-43.

Chang, S.D., Ro, T. 1996. "Pressure Drop of Pure HFC Refrigerants and Their Mixtures Flowing in Capillary Tubes", Int. J. Multiphase Flow, vol. 22(3), 551-61.

Collier, J.G., Thome, J.R. 1996." Convective Boiling and Condensation", 3rd ed., Oxford Science, Oxford.

Fiorelli, F.A.S., et al. 1998. "Numerical Study on Refrigerant Mixtures Flow in Capillary Tubes", Proc. 1998 Int. Refrigeration Conference, West Lafaiette, USA.

Fiorelli,F.A.S. et al. 1999, "Analysis of R-410A and R407C Flow Through Capillary Tubes Using a Separated Flow Model", Proc. 20th Int. Congr. Refrigeration, Sydney, Australia.

Fiorelli,F.A.S. 2000, "Analysis of HCFC 22 Alternative Refrigerants Flow Through Adiabatic Capillary Tubes" (in portuguese), Doctoral Thesis, University of São Paulo, São Paulo, Brazil, 183 p.

Fiorelli, F.A.S., et al. 2002. "Experimental Analysis of Refrigerant Mixtures Flow Through Adiabatic Capillary Tubes", Exp. Thermal and Fluid Sc. vol. 26(5), 499-512.

Idelcik, I.E. 1960. "Memento des Pertes de Charge", Eyrolles Editeur, Paris.

Jung, D. et al. 1999. "Capillary Tube Selection for HCFC22

Alternatives”, Int. J. Refrigeration, vol. 22, 604-14.
Kakaç, S. et al. 1987. "Handbook of Single-Phase Convective Heat Transfer", John Wiley, New York.

Meyer, J.J., Dunn, W.E. 1998. "New insights into the behavior of the metastable region of an operating capillary tube", HVAC\&R Res., vol 4(1), 105-15.

Motta, S.Y. et al. 2000. "Critical Flow of Refrigerants Through Adiabatic Capillary Tubes: Experimental Study of Zeotropic Mixtures R-407C and R-404A", ASHRAE Trans., vol 106(1), 534-49.

Pate, M.B. 1982. "A Theoretical and Experimental Analysis of Capillary Tube-Suction Line Heat Exchangers", Ph.D. Thesis, Purdue University.

Sami, S.M. Tribes, C. 1998. "Numerical Prediction of Capillary Tube Behaviour with Pure and Binary Alternative Refrigerants", Applied Thermal Eng., vol 18(6), 491-502.

Sami, S.M., et al. 1998. "Modelling of Capillary Tubes Behaviour with HCFC 22 Ternary Alternative Refrigerants”, Int. J. Energy Res., Vol. 22, 843-55.

Wei, C.Z., et al. 1999. "An Experimental Study of the Performance of Capillary Tubes for R-407C Refrigerant", ASHRAE Trans., Vol. 105(2), 634-8.

Whalley,P.B. 1996. "Two-Phase Flow and Heat Transfer". Oxford Science, Oxford. 